\title{
Desenvolvimento e aplicação de um método de avaliação do comportamento de risco em condutores
}

Amanda Bifano Balbinot

Orientador: Prof. Dr. Milton Antônio Zaro

Coorientadora: Profa. Dra. Maria Isabel Timm

Banca: Prof. Dr. Dante Augusto Couto Barone (PPGIE/UFRGS), Prof. Dr. Luiz Afonso S. Senna (UFRGS/ Eng. Da Produção), Profa. Dra. Irani Iracema de Lima Argimon (PUC-RS)

Data da defesa: 11 de abril de 2011

O interesse principal desta pesquisa é a investigação, o desenvolvimento e a aplicação de um método que permita identificar e avaliar a ocorrência de comportamentos de risco em condutores com habilitação categoria $B$, na cidade de Porto Alegre. Esse método está fundamentado em trabalhos que caracterizam o cometimento de erros, lapsos e violações que ensejam o envolvimento em acidentes de trânsito. Tais trabalhos embasam a elaboração e a discussão deste estudo e também a teoria da Homeostase do Risco, as funções psicológicas, cognitivas e os aspectos legais envolvidos no ato de dirigir, assim como o desenvolvimento de jogos e simuladores de condução. Os instrumentos utilizados constituem-se de um jogo digital de situações de trânsito e de um questionário digital sobre o comportamento de condutores, ambos desenvolvidos com base no Driver Behavior Questionnaire (DBQ) ${ }^{1}$ e em dados estatísticos sobre as infrações mais cometidas. Os comportamentos de risco que apresentaram maior incidência, com a aplicação do método, correspondem aos dados estatísticos sobre as principais infrações cometidas por condutores. A correlação entre os dados obtidos com o Questionário e o Jogo demonstrou, na amostra estudada, não haver associação significativa entre os dois instrumentos na maioria das situações abordadas. Isso denota não haver relação direta entre os instrumentos, vistos aqui como independentes, mas complementares. Dessa forma, à luz do método proposto, podem-se tornar maiores as possibilidades de análise sobre o comportamento de risco no trânsito, bem como com a continuidade de pesquisas na área. A identificação de forma precoce de fatores preditores de comportamentos de risco tem sua relevância por corroborar para a efetividade das intervenções preventivas.

Palavras-chave: Comportamento de risco em condutores. Jogo de trânsito. Método de avaliação.

\section{Referência:}

BALBINOT, Amanda Bifano. Desenvolvimento e aplicação de um método de avaliação do comportamento de risco em condutores. Orientador: Milton Antônio Zaro. Coorientadora: Maria Isabel Timm. 2011. Tese (Doutorado) - Programa de Pós-Graduação em Informática na Educação, Centro de Estudos Interdisciplinares em Novas Tecnologias da Educação, Universidade Federal do Rio Grande do Sul, 2011, Porto Alegre, BR-RS. Membros da Banca Examinadora: Dante Augusto Couto Barone (PPGIE/UFRGS), Luiz Afonso S. Senna (UFRGS/ Eng. Da Produção), Irani Iracema de Lima Argimon (PUC-RS). Data da defesa: 11/04/2011.

\footnotetext{
${ }^{1}$ Questionário sobre o Comportamento do Motorista (QCM)
} 